\title{
Gluten-free food database: The nutritional quality and cost of packaged gluten-free foods
}

Benjamin Missbach, Lukas Schwingshackl, Alina Billmann, Aleksandra Mystek, Melanie Hickelsberger, Gregor Bauer, Jürgen König Notwithstanding a growth in popularity and consumption of gluten-free (GF) food products, there is a lack of substantiated analysis of the nutritional quality compared with their gluten-containing counterparts. To put GF foods into proper perspective both for those who need it (patients with celiac disease) and for those who do not, we provide contemporary data about cost and nutritional quality of GF food products. The objective of this study is to develop a food composition database for 7 discretionary food categories of packaged GF products. Nutrient composition, nutritional information and cost of foods from $63 \mathrm{GF}$ and 126 gluten-containing counterparts were systematically obtained from 12 different Austrian supermarkets. The nutrition composition (macro and micronutrients) was analyzed by using two nutrient composition databases in a stepwise approximation process. A total of 63 packaged GF foods were included in the analysis representing a broad spectrum of different GF categories (flour/bake mix, bread and bakery products, pasta and cereal-based food, cereals, cookies and cakes, snacks and convenience food). Our results show, that the protein content of GF products is $>2$ fold lower across $57 \%$ of all food categories. In $65 \%$ of all GF foods, low sodium content was observed (defined as $<120 \mathrm{mg} / 100 \mathrm{~g}$ ). Across all GF products, $19 \%$ can be classified as source high in fiber (defined as $>6 \mathrm{~g} / 100 \mathrm{~g}$ ). On average, GF foods were substantially higher in cost, ranging from $+205 \%$ (cereals) to $+267 \%$ (bread and bakery products) compared to similar glutencontaining products. In conclusion, our results indicate that for GF foods no predominant health benefits are indicated, in fact some critical nutrients must be considered when being on a GF diet. For individuals with celiac disease, the GF database provides a helpful tool to identify the food composition of their medical diet. For healthy consumers, replacing gluten-containing products with GF foods is aligned with substantial cost differences but GF foods do not provide additional health benefits from a nutritional perspective. 


\section{Gluten-free food database: The nutritional quality and cost 2 of packaged gluten-free foods.

4 Benjamin Missbach ${ }^{1 \S}$, Lukas Schwingshackl ${ }^{2}$, Alina Billmann ${ }^{1}$, Aleksandra Mystek ${ }^{1}$, Melanie

5 Hickelsberger ${ }^{1}$, Gregor Bauer ${ }^{3}$, Jürgen König ${ }^{1}$

6

$7 \quad{ }^{1}$ Department of Nutritional Sciences, University of Vienna, Althanstrasse 14, 1090 Vienna,

8 Austria

$9 \quad{ }^{2}$ German Institute of Human Nutrition, Arthur-Scheunert-Allee 114-116

1014558 Nuthetal, Germany

$11{ }^{3}$ Department of Internal Medicine I, Kaiser-Franz-Josef Spital Vienna, Kundratstraße 3, 1100

12 Vienna

14 §Corresponding author

15 Email addresses:

BM: benjamin.missbach@univie.ac.at

17 LS: lukas.schwingshack1@univie.ac.at

AB: alina.billmann@gmx.de

AM: a.mystek@hotmail.com

MH: melanie.hickelsberger@gmail.com

GB: gregor_bauer@gmx.net

22

JK: juergen.koenig@univie.ac.at 


\section{Abstract}

26 Notwithstanding a growth in popularity and consumption of gluten-free (GF) food products,

27 there is a lack of substantiated analysis of the nutritional quality compared with their gluten-

28 containing counterparts. To put GF foods into proper perspective both for those who need it

29 (patients with celiac disease) and for those who do not, we provide contemporary data about cost

30 and nutritional quality of GF food products. The objective of this study is to develop a food

31 composition database for 7 discretionary food categories of packaged GF products. Nutrient

32 composition, nutritional information and cost of foods from $63 \mathrm{GF}$ and 126 gluten-containing

33 counterparts were systematically obtained from 12 different Austrian supermarkets. The nutrition

34 composition (macro and micronutrients) was analyzed by using two nutrient composition

35 databases in a stepwise approximation process. A total of 63 packaged GF foods were included

36 in the analysis representing a broad spectrum of different GF categories (flour/bake mix, bread

37 and bakery products, pasta and cereal-based food, cereals, cookies and cakes, snacks and

38 convenience food). Our results show, that the protein content of GF products is $>2$ fold lower

39 across $57 \%$ of all food categories. In $65 \%$ of all GF foods, low sodium content was observed

40 (defined as $<120 \mathrm{mg} / 100 \mathrm{~g}$ ). Across all GF products, 19\% can be classified as source high in fiber

41 (defined as $>6 \mathrm{~g} / 100 \mathrm{~g}$ ). On average, GF foods were substantially higher in cost, ranging from

$42+205 \%$ (cereals) to $+267 \%$ (bread and bakery products) compared to similar gluten-containing

43 products. In conclusion, our results indicate that for GF foods no predominant health benefits are

44 indicated, in fact some critical nutrients must be considered when being on a GF diet. For

45 individuals with celiac disease, the GF database provides a helpful tool to identify the food

46 composition of their medical diet. For healthy consumers, replacing gluten-containing products

47 with GF foods is aligned with substantial cost differences but GF foods do not provide additional 
48 health benefits from a nutritional perspective. 


\section{Introduction}

50 Individuals with celiac disease (CD) show high levels of intestinal inflammation when exposed 51 to gluten-containing foods (Ludvigsson et al. 2013; Rubio-Tapia et al. 2013). In western 52 countries, the prevalence for CD is estimated at approximately 1\% (Golley et al. 2015; Gujral et 53 al. 2012). Clinically, as direct response to gluten and related prolamines in a diet, immunological 54 processes damage intestinal mucosa and lead to villous atrophy, crypt hyperplasia and nutrient malabsorption (Dickson et al. 2006; Husby et al. 2012). To get full remission of the symptoms, excluding gluten-containing cereals (e.g. wheat, rye, barley) in a strict lifelong gluten-free (GF) diet is indicated (El-Chammas \& Danner 2011; Green 2009). The nutritional quality of GF products that replace cereal-based foods is pivotal for patients with CD. Previous research showed that GF food products differ in their nutrient content compared to gluten-containing counterparts (Mazzeo et al. 2015; Miranda et al. 2014). In addition, a recent evaluation of more than $600 \mathrm{GF}$ foods in Australian supermarkets showed that it is unlikely that GF foods have health benefits for individuals without $\mathrm{CD}$, in particular due to the reported lower protein content in GF compared to non-GF products (Wu et al. 2015). However, contemporary data reporting the nutritional quality is scarce (Staudacher \& Gibson 2015), although the popularity of GF food products is increasing among consumers (Marketsandmarkets, 2013). To the best of our knowledge, no database with respect to nutritional quality for packaged GF food is available in

67 German-speaking countries.

For CD patients, adhering to a restrictive GF diet can be challenging for several reasons. First,

69 food choices are essentially limited because cereal products are staple foods in western countries

70 and play a predominant role in a regular diet (e.g bread or pasta). Second, a wide range of

71 processed foods contain gluten-based products as additional ingredients. Prior to consumption of 
72 these foods, a detailed examination of the ingredient list has to be performed to avoid being 73 exposed to gluten. This requires fundamental nutritional knowledge and a high level of self74 discipline (Mulder et al. 2015). Third, 20-38\% of patients with CD have some nutritional 75 deficiencies due to their medical condition (Kinsey et al. 2008; Saturni et al. 2010); e.g iron 76 deficiency, deficiency in $\mathrm{B}$ vitamins $\left(\mathrm{B}_{6}, \mathrm{~B}_{12}\right)$ and trace minerals (e.g zinc) (Harris et al. 2012;

77 Theethira \& Dennis 2015). In a nutshell, patients with CD are in need to structure their diet in a 78 strict manner to maintain a positive long-term health outcome. Therefore, GF products have been 79 developed as alternatives to cereal-based formulations. A wide range of products based on teff, 80 amaranth, buckwheat or quinoa are now available for consumers exploring different alternatives 81 to enhance sensory properties and shelf-life (Gallagher et al. 2004; Pellegrini \& Agostoni 2015).

82 Likewise, GF products are very popular among consumers without CD, which has led to almost 83 exponential rise in sales for GF products over the last decade (Marketsandmarkets, 2013; Strom, 84 2014). Mardini et al. (2015) report updated US data from the National Health and Nutrition 85 Examination Survey (NHANES) from 2009-2012. From all study participants (14.701 86 participants), $0.9 \%$ adhered to a GF diet, even though $85 \%$ of this group was never diagnosed 87 with $\mathrm{CD}$ and $99 \%$ had negative serological markers for CD. For the majority of consumers, GF 88 products are perceived as healthier than conventional products (Marcason 2011). While evidence 89 for this assumption is not based on solid data (De Giorgio et al. 2015; Gaesser \& Angadi 2012), 90 food companies continue to market GF foods as healthier and charge premium price for their 91 products (Singh \& Whelan 2011; Stevens \& Rashid 2008). Still, there is no solid data putting GF 92 products into proper perspective about nutritional quality and product costs.

93 To provide better consumer information, the present work is the first attempt to build a nutrient 94 composition database for packaged GF products available in one German-speaking country 
95 (Austria). The aim of the current study is to present data from GF foods representing the main

96 sources of cereal-based food and analyze their nutrient content and cost.

98 Materials \& Methods

99 We used a matched food sample procedure to analyze the nutrient content of packaged GF foods

100 available on the Austrian Market. We grouped packaged GF foods with matching gluten-

101 containing foods from two nutrition databases, estimated their nutrient content by using a step-

102 by-step estimation process and compared the nutritional quality. We defined primary

103 (macronutrient and energy content) and secondary outcome parameter (micronutrients and cost

104 of the products) for further analysis.

105 Food products included

106 Between fall 2014 and spring 2015, packaged GF foods from 19 brands were obtained from three

107 main supermarket chains in Austria in 12 different branches across Vienna. We selected 162

108 packaged GF foods from 7 different food categories representing the majority of consumed

109 processed foods that are originally based on cereal formulations for by celiac patients (Martin et

110 al. 2013). We only analyzed packaged GF foods marked with the European gluten-free label

111 (Commission Regulation (EC) No 41/2009), exluded foods with non-verified gluten-free labels

112 and excluded foods from categories that are not gluten-based in their original formulation.

113 Following food categories were analyzed: flour/bake mix, bread and bakery products, pasta and

114 cereal-based food, cereals, cookies and cakes, snacks and convenience food (for detailed listing,

115 see supplementary material). Additionally, we assessed the cost for each product.

116 Both, food quality as well as cost ranged widely within individual food products. To minimize

117 this within-product range and provide more homogenous data in both target variables (nutritional

118 quality; product cost), we matched two gluten-containing foods differing in cost range (one 
119 budget and one pricier product) for each GF food. From originally 162 identified packaged GF

120 foods, we excluded duplicates (86) and foods with incomplete nutrient information (13 foods)

121 (see flow diagram and detailed list of exclusion in the supplementary material). Our final sample

122 consists of $63 \mathrm{GF}$ and 126 similar gluten-containing foods for subsequent nutrient content

123 matching procedure.

\section{Step-by-step estimation process for nutrient content}

125 The selected GF foods were matched with two similar gluten-containing foods available in two 126 different databases used in the Austrian Nutrition Surveys (BLS 3.02 Max Rubner Institute, 127 Germany; Austrian Nutrient Database: ÖNWT, dato denkwerkzeuge, Vienna, Austria). We used 128 a Microsoft Excel worksheet to compile the composition in macro- and micronutrients of the GF

129 foods per $100 \mathrm{~g}$ in its raw form. We imputed the quantity for each ingredient in a descending 130 order. In a second step, we estimated the quantity of each ingredient for every product based on

131 the percentage of the final recipe and its rank order reported on the label (theoretical nutrient 132 composition). Furthermore we compared the theoretical macronutrient composition of the food 133 with the given information on the food label. The process was reiterated by adjusting the 134 percentage of the different ingredients until the final results reflected the values of energy 135 content reported on the food label. To assess the precision of this procedure we calculated the 136 estimation precision (theoretical nutrient content/nutrient content on the food label in \%). The 137 precision for the estimation of all macronutrients was very good and within an overall variation 138 range of $7 \%$ (for detailed listing, see supplementary material).

139 As a result of this process we could estimate the amount of ingredients available in the GF 140 products and extrapolate the nutritional components for following ingredients and nutrients: 141 water $(\mathrm{g} / 100 \mathrm{~g})$, sugar $(\mathrm{g} / 100 \mathrm{~g})$, energy content (in kcal/100g), macronutrients (carbohydrates, 
142 proteins, total fat, saturated fatty acids, monounsaturated fatty acids (MUFA), polyunsaturated

143 fatty acids (PUFA), fibre; all in $\mathrm{g} / 100 \mathrm{~g}$ ), cholesterol (mg/100g), minerals (i.e. Iron, Calcium,

144 Sodium, Potassium, Phosphorous and Zinc; all in $\mathrm{mg} / 100 \mathrm{~g}$ ) and vitamins (Vitamin E, Thiamin,

145 Riboflavin, Niacin, and Vitamin C; all in mg/100g; Vitamin D, Retinol, $\beta$-carotene equivalents in $146 \mu \mathrm{g} / 100 \mathrm{~g})$.

147

148 Statistical Analyses and Availability of the Database

149 Statistical analyses were conducted using IBM SPSS Statistics 22. Unpaired t-test was used to 150 compare means; bivariate comparisons were tested by $\chi^{2}$ test. The Bonferroni post-hoc test was

151 used to correct for multiple comparisons; p-values $<0.05$ were classified as significant. Post-hoc

152 power analysis was calculated by the difference between two independent means with $\mathrm{G}^{*}$ Power $153 \quad 3.1 .9$ (Erdfelder et al. 2009).

154 The Gluten-Free Food Database (Austria) can be accessed via the science collaboration platform:

155 Open Science Framework. Contributions to the dataset can be made upon request and 156 registration via the online platform (Open Science Framework).

\section{Results}

159 The database provides quantitative information of macro- and micronutrients of the GF product.

160 It contains nutrient data present in the traditional databases of gluten-containing foods (see Table 1611 and Table 2).

162 Primary Outcome Parameter: Macronutrient and energy content

163 Across all food categories, energy content ranged between $270.5 \pm 13.5 \mathrm{kcal} / 100 \mathrm{~g}$ (category:

164 bread and bakery products) to $398.8 \pm 25.4 \mathrm{kcal} / 100 \mathrm{~g}$ (category: snacks). Across all food 
165 categories, energy content, carbohydrate, total fat, saturated fatty acids, fiber and sugar did not

166 differ between $\mathrm{GF}$ and products gluten-containing products $(\mathrm{F}<1 ; \mathrm{p}>0.05)$.

167 Protein content was significantly lower in GF foods $(5.8 \pm 3.7 \mathrm{~g} / 100 \mathrm{~g})$ than gluten-containing

168 foods $(8.6 \pm 2.9 \mathrm{~g} / 100 \mathrm{~g}) ; \mathrm{F}=31.9 ; \mathrm{p}<0.01$ (see Figure 1). Lower protein content was present in

1694 out of 7 food categories (flour/bake mix, bread and bakery products, pasta and cereal-based

170 products and snacks). In flour/bake mix products, the average protein content was $4.6 \pm$

$1713.4 \mathrm{~g} / 100 \mathrm{~g}$ for GF and $9.9 \pm 2 \mathrm{~g} / 100 \mathrm{~g}$ for their gluten-containing counterparts (see Table 3 ).

172 Secondary Outcome Parameter: Micronutrients and product cost

173 Overall, sodium content in gluten-containing foods $(448.9 \pm 704.6 \mathrm{mg} / 100 \mathrm{~g})$ did not differ

174 compared to GF foods $(373.5 \pm 569.2 \mathrm{mg} / 100 \mathrm{~g} ; \mathrm{F}<1, \mathrm{p}>0.05)$. In one category (cereal

175 products), sodium content was higher in GF foods. Across all three analyzed GF cereal products,

176 sodium content was $491.3 \pm 91.6 \mathrm{mg} / 100 \mathrm{~g}$ while in gluten-containing foods, sodium content was

$177160.7 \pm 139.3 \mathrm{mg} / 100 \mathrm{~g}(\mathrm{~F}=13.4 ; \mathrm{p}<0.01)$. For bread and bakery products, sodium content was

178 lower in GF products $(388.4 \pm 206.4 \mathrm{mg} / 100 \mathrm{~g})$ compared to gluten-containing foods $(581.9 \pm$

$179290.3 \mathrm{mg} / 100 \mathrm{~g} ; \mathrm{F}=4.5 ; \mathrm{p}<0.05)$. Across all other categories, sodium content did not differ

180 significantly. $27 \%$ of all products showed high sodium content (defined as $>500 \mathrm{mg} / 100 \mathrm{~g}$,

181 Nutrition and Health Claim $N^{\circ} 1924 / 2006$ (2006), this did not differ between GF and gluten-

182 containing foods $\left(\chi^{2}[1]=1.94 ; p>0.05\right)$. In contrast, $65 \%$ of GF and $61 \%$ of gluten-containing

183 foods showed low sodium content (defined as $<120 \mathrm{mg} / 100 \mathrm{~g}$, Nutrition and Health Claim

$184 \mathrm{~N}^{\circ} 1924 / 2006(2006)$.

185 Potassium content was significantly lower in GF products $(190.4 \pm 160 \mathrm{mg} / 100 \mathrm{~g})$ than in products

186 containing gluten $(247.5 \pm 130 \mathrm{mg} / 100 \mathrm{~g} ; \mathrm{F}=6.9 ; \mathrm{p}<0.05)$. This difference was present in 2 out

187 of 7 food categories (pasta and cereal-based products; snacks), while all other categories did no 
188 show significant differences. Moreover, zinc content was significantly lower in GF pasta 189 products $(1.9 \pm 0.9 \mathrm{mg} / 100 \mathrm{~g}$ vs. $4.6 \pm 0.4 \mathrm{mg} / 100 \mathrm{~g} ; \mathrm{F}=82.1 ; \mathrm{p}<0.01)$. GF Pasta products

190 showed higher fiber content $(7.9 \pm 4.2 \mathrm{~g} / 100 \mathrm{~g})$ when compared to gluten-containing products $(3.7$

$191 \pm 0.7 \mathrm{~g} / 100 \mathrm{~g} ; \mathrm{F}=13.6 ; \mathrm{p}<0.01)$. Across all GF products, $19 \%$ can be classified as source high in

192 fiber (defined as $>6 \mathrm{~g} / 100 \mathrm{~g}$, Nutrition and Health Claim $\mathrm{N}^{\circ}$ 1924/2006 (2006).

193 Substantial cost disparities were present between GF products and gluten-containing products.

194 On average, the cost for GF products ranged from $2.95 €$ (white flour) to $80.80 €$ per $\mathrm{kg}$ (Wafer,

195 Oblaten) and was significantly higher in GF products $(11.58 \pm 11.43 €)$ compared to gluten-

196 containing products $(6.62 \pm 5.36 € ; \mathrm{F}=53.1 ; \mathrm{p}<0.01)$ across all product categories. Within bread

197 and bakery products, GF food were $+267 \%$ more expensive than similar gluten-containing

198 products. The lowest cost disparity ( $+205 \%$ higher cost for GF products) was observed for cereal 199 products (Figure 2). 


\section{Discussion}

201 The present study is the first attempt to present a large dataset comparing GF foods and gluten202 containing products available in one German-speaking country (Austria). The data showed that 203 there is great variability between GF foods and gluten-containing products for specific nutrients.

204 One key finding of this study is that protein content was significantly lower in GF foods across 205 all staple foods. In flour/bake mix products, the average protein content was $>2$ fold lower 206 compared to their gluten-containing counterparts. This finding is in line with previous findings

207 (Wu et al. 2015), except that we did not observe significant differences in total fat, saturated fat, 208 PUFA and MUFA in our products (Kulai \& Rashid 2014; Matos Segura \& Rosell 2011; Miranda 209 et al. 2014). Only in pasta and cereal-based products, MUFA content was significantly higher in 210 GF foods. The low amount of proteins in GF foods can be explained by their formulation. In GF 211 formulations, carbohydrate-rich but protein-poor ingredients are used, such as white rice flour, 212 tapioca or potato starch (Mezaize et al. 2009). This can lead to lower protein content in GF 213 foods, which may be a reasonable explanation for the observed differences in our data.

214 Reports about protein intake and its clinical relevance for celiac patients is conflicting. In a 215 prospective study comparing dietary intake from 88 celiac patients (7-day dietary record) with 216 data from non-celiac individuals from the German National Diet and Nutrition Survey (NVS II), 217 no differences in protein intake for males or females were observed (Martin et al. 2013). On the 218 other hand, Miranda et al. (2014) analyzed 58 adults with CD and showed that protein intake was 219 lower in women who were on a GF diet compared to a diet containing gluten. In this study, the 220 protein content of breads was almost one third lower than their equivalent foods with gluten. In 221 our dataset GF breads contained half of the proteins compared to regular breads with gluten.

222 Addtionally, in a cross-sectional study, van Hees et al. (2015) compared dietary intake of amino 
223 acids in $77 \mathrm{CD}$ patients. They found that compared to contrasted by 33 healthy controls a GF diet

224 with good adherence resulted in significantly lower amino acid concentrations in blood (tyrosine,

225 phenylalanine and tryptophan). The authors argue that both, a reduced intake of vegetable

226 protein and malabsorption as a results of CD may be responsible for this result. The findings of

227 our study suggest that reduced protein content in GF products may facilitate problematic protein

228 intake in $\mathrm{CD}$ patients and should be considered in dietary counseling.

229 In $65 \%$ of all analyzed GF foods, low sodium content (defined as $<120 \mathrm{mg} / 100 \mathrm{~g}$, Nutrition and

230 Health Claim N¹924/2006 (2006) was observed. Interestingly, in bread and bakery products,

231 sodium content was lower compared to gluten-containing foods. The lower amount of sodium in

232 GF bread may be accounted for the joint initiative „Weniger Salz is g'sünder“ with the aim to

233 reduce salt in bread and bakery products by $15 \%$ by 2015 initiated by the Austrian Ministry of

234 Health (2011) and the Industrial Bakers of Austria (Lloyd-Williams et al. 2014). Foods from the

235 datasets used in this study contained nutrient information that were assessed prior to this

236 initiative (started 2011), which may be a possible explanation for this discrepancy.

237

238 Limitations

239 Some limitations of the present study should be taken into account. First, we did not analyze the

240 nutritional composition of GF foods through direct chemical analysis, but only estimated the data

241 from nutrient content by deriving data from two nutrient databases. Direct chemical analysis is

242 the gold standard to estimate the nutrient composition of food. Neverthless, previous studies

243 have shown that estimating the nutrient composition of GF food via indirect analysis is a valid

244 method, likewise (Mazzeo et al. 2015; Miranda et al. 2014; Wu et al. 2015). Additionally

245 nutrient data shown on food labels provided by the food industry are commonly based on 
246 estimation of nutrient content of the ingredients rather than direct chemical analysis of the food 247 products (Pennington 2008).

248 A second limitiation of the study is the small sample size of the analyzed products. Due to the 249 rigorous exclusion steps applied in this study, we only analyzed 63 from originally 162 identified 250 GF foods. We only analyzed foods that are originally based on cereal formulations. In some 251 categories, low numbers of GF foods were included (e.g. category cereals only three items; 252 category flour/bake mix only five items). Hence, post-hoc power analysis revealed that in the

253 case of e.g protein content in GF and gluten-containing food groups in flour/bake mix products, 254 statistical power (1- $\beta$ ) was still high at $95.7 \%$. Nevertheless, this is only the first step to build a 255 database for GF products in Austria, and we will be extending the database for future 256 investigations. Therefore the provided number of foods is a solid starting point for further 257 analysis.

258 Finally, it should be noted that we only included data from products sold in one German259 speaking country (Austria), while a majority of GF products are well distributed across European 260 countries, translating our findings to other countries should be interpreted conservatively.

261 Nevertheless, this study improves our knowledge about the nutritional quality of GF foods and 262 secondly, the applied methodological strategy holds a great potential to consolidate data from 263 other countries to form a transnational database on GF products.

\section{Implications of the present research}

266 To put our findings into perspective about the ongoing discussion if choosing GF foods holds

267 potential advantage or disadvantages for consumers, it is important to note that GF products are 268 very popular among consumers without $\mathrm{CD}$. In fact, GF foods are increasingly purchased by 
269 individuals without CD (Silvester et al. 2015). A report by Dunn et al. (2014) showed that only

$27057 \%$ consume GF foods for medical reasons, while for almost half of the consumers other factors

271 e.g. lifestyle and positive health association are important for purchasing GF foods. This trend is

272 reflected in worldwide sales numbers as well. Between 2004 and 2011 the market for GF

273 products grew at an annual growth rate of $28 \%$ (Sapone et al. 2012). The global GF product

274 market is projected to reach a value of $\$ 6206$ million, growing at a compounded annual growth

275 rate of $10.2 \%$ by 2018 (Marketsandmarkets, 2013). This implies that the GF product market

276 represents a very prosperous market in food and beverages. In addition, there is an ongoing

277 discussion about the prevalence of nonceliac gluten sensitivity (NCGS) in the general

278 population. For individuals suffering from NCGS, adhering to a GF diet could also be beneficial

279 in the remission of their symptoms (El-Chammas \& Danner 2011). Nevertheless, the majority of

280 clinical evidence NCGS remain inconsistent and rather controversial (Biesiekierski et al. 2013).

281 From a public health perspective, there is no need to adhere to a GF diet for consumers without

282 diagnosed CD (Catassi et al. 2013; De Giorgio et al. 2015; Molina-Infante et al. 2015).

283 Still, the question why GF products are perceived as healthier for consumers without CD is of

284 relevance (Dunn et al. 2014). On a behavioral level, the increased perceived healthfulness may

285 be explained by the 'health halo' effect, which states that products that are labelled as 'healthier'

286 (e.g. low-fat label) can mislead consumers about other important nutritional elements, e.g.

287 energy content and portion sizes (Faulkner et al. 2014). The 'health halo' effect can also lead to

288 some undesired behavioral effects such as increased consumption and poor caloric estimates

289 (Ebneter et al. 2013).

290 Marketers tap into the perceived healthfullness which reflects, besides the increased production

291 cost of GF products, in the overall higher cost of GF products. In our dataset, the cost for all 
292 analyzed GF products was $205-267 \%$ higher than for conventional foods. This finding is in line 293 with previous findings (Kulai \& Rashid 2014; Lee et al. 2007; Singh \& Whelan 2011; Stevens \& 294 Rashid 2008). In fact, Singh \& Whelan (2011) report even higher cost disparities for GF foods 295 ranging from $70-510 \%$.

296

\section{Conclusions}

298 In conclusion, this study presents the first findings for a thorough analysis of GF products in a 299 German-speaking country. There are some marked differences between GF and gluten300 containing foods. Based on the nutrient composition of GF foods, our results indicate that GF 301 foods are not aligned with particular health benefits, but rather show critical nutrients which 302 should be considered in future formulations. The findings of our study indicate that re-thinking 303 the health aspects ascribed to GF products, at least based on nutrient content of GF foods, should

304 be considered and publicly communicated. Especially in the face of a growing market share, 305 common health misconceptions should be kept in mind when discussing GF products. 
306

307

308

309

310

311

312

313

314

315

316

317

318

319

320

321

322

323

324

325

326

327

328

329

330

331

332

333

334

335

336

337

338

339

340

341

342

343

344

345

346

347

348

349

350

351

\section{References}

Austrian Ministry of Health. 2011. http://bmg.gv.at/site2/Schwerpunkte/Ernaehrung/Empfehlungen/Kampagne_Weniger_Salz_ist _g_suender_. (accessed 23 September 2015)

Biesiekierski JR, Muir JG, and Gibson PR. 2013. Is gluten a cause of gastrointestinal symptoms in people without celiac disease? Current allergy and asthma reports 13:631-638.

Catassi C, Bai JC, Bonaz B, Bouma G, Calabrò A, Carroccio A, Castillejo G, Ciacci C, Cristofori F, and Dolinsek J. 2013. Non-celiac gluten sensitivity: the new frontier of gluten related disorders. Nutrients 5:3839-3853.

Commission Regulation (EC) No 41/2009. 2009. Commission Regulation (EC) No 41/2009 of 20 January 2009 concerning the composition and labelling of foodstuffs suitable for people intolerant to gluten (Text with EEA relevance)

De Giorgio R, Volta U, and Gibson PR. 2015. Sensitivity to wheat, gluten and FODMAPs in IBS: facts or fiction? Gut.

Dickson BC, Streutker CJ, and Chetty R. 2006. Coeliac disease: An update for pathologists. Journal of Clinical Pathology 59:1008-1016.

Dunn C, House L, and Shelnutt KP. 2014. Consumer Perceptions of Gluten-Free Products and the Healthfulness of Gluten-Free Diets. Journal of Nutrition Education and Behavior 46:S184-S185.

Ebneter DS, Latner JD, and Nigg CR. 2013. Is less always more? The effects of low-fat labeling and caloric information on food intake, calorie estimates, taste preference, and health attributions. Appetite 68:92-97.

El-Chammas K, and Danner E. 2011. Gluten-free diet in nonceliac disease. Nutrition in Clinical Practice 26:294-299.

Erdfelder E, Faul F, Buchner A, and Lang AG. 2009. Statistical power analyses using G*Power 3.1: Tests for correlation and regression analyses. Behavior Research Methods 41:1149-1160.

Fasano A, Sapone A, Zevallos V, and Schuppan D. 2015. Nonceliac Gluten Sensitivity. Gastroenterology 148:1195-1204.

Faulkner G, Pourshahidi L, Wallace J, Kerr M, McCaffrey T, and Livingstone M. 2014. Perceived 'healthiness' of foods can influence consumers' estimations of energy density and appropriate portion size. International Journal of Obesity 38:106-112.

Gaesser GA, and Angadi SS. 2012. Gluten-free diet: imprudent dietary advice for the general population? J Acad Nutr Diet 112:1330-1333.

Gallagher E, Gormley T, and Arendt E. 2004. Recent advances in the formulation of gluten-free cerealbased products. Trends in Food Science \& Technology 15:143-152.

Golley S, Corsini N, Topping D, Morell M, and Mohr P. 2015. Motivations for avoiding wheat consumption in Australia: results from a population survey. Public health nutrition 18:490-499.

Green PH. 2009. Mortality in celiac disease, intestinal inflammation, and gluten sensitivity. Jama 302:1225-1226.

Gujral N, Freeman HJ, and Thomson AB. 2012. Celiac disease: prevalence, diagnosis, pathogenesis and treatment. World J Gastroenterol 18:6036-6059.

Harris LA, Park JY, Voltaggio L, and Lam-Himlin D. 2012. Celiac disease: Clinical, endoscopic, and histopathologic review. Gastrointestinal Endoscopy 76:625-640.

Husby S, Koletzko S, Korponay-Szabó IR, Mearin ML, Phillips A, Shamir R, Troncone R, Giersiepen K, Branski D, Catassi C, Lelgeman M, Mäki M, Ribes-Koninckx C, Ventura A, and Zimmer KP. 2012. European society for pediatric gastroenterology, hepatology, and nutrition guidelines for the diagnosis of coeliac disease. J Pediatr Gastroenterol Nutr 54:136-160. 
352

353

354

355

356

357

358

359

360

361

362

363

364

365

366

367

368

369

370

371

372

373

374

375

376

377

378

379

380

381

382

383

384

385

386

387

388

389

390

391

392

393

394

395

396

397

Kinsey L, Burden ST, and Bannerman E. 2008. A dietary survey to determine if patients with coeliac disease are meeting current healthy eating guidelines and how their diet compares to that of the British general population. Eur J Clin Nutr 62:1333-1342.

Kulai T, and Rashid M. 2014. Assessment of Nutritional Adequacy of Packaged Gluten-free Food Products. Canadian Journal of Dietetic Practice and Research 75:186-190.

Lee A, Ng D, Zivin J, and Green P. 2007. Economic burden of a gluten-free diet. Journal of Human Nutrition and Dietetics 20:423-430.

Lloyd-Williams F, Bromley H, Orton L, Hawkes C, Taylor-Robinson D, Martin O, McGill R, Anwar E, Hyseni L, and Moonan M. 2014. Smorgasbord or symphony? Assessing public health nutrition policies across 30 European countries using a novel framework. BMC Public Health 14:1195.

Ludvigsson JF, Rubio-Tapia A, Van Dyke CT, Melton LJ, Zinsmeister AR, Lahr BD, and Murray JA. 2013. Increasing incidence of celiac disease in a North American population. American Journal of Gastroenterology 108:818-824.

Marcason W. 2011. Is there evidence to support the claim that a gluten-free diet should be used for weight loss? J Am Diet Assoc 111:1786.

Mardini H, Westgate P, and Grigorian A. 2015. Racial Differences in the Prevalence of Celiac Disease in the US Population: National Health and Nutrition Examination Survey (NHANES) 2009-2012. Digestive Diseases and Sciences 60:1738-1742.

Marketsandmarkets.com. 2013. Gluten-free products market by type, sales channel and geography: global trends and forecasts to 2018. http://www.marketsandmarkets.com/Market Reports/gluten-free-products-market-738.html (accessed 12 July 2015)

Martin J, Geisel T, Maresch C, Krieger K, and Stein J. 2013. Inadequate nutrient intake in patients with celiac disease: Results from a German dietary survey. Digestion 87:240-246.

Matos Segura ME, and Rosell CM. 2011. Chemical Composition and Starch Digestibility of Different Gluten-free Breads. Plant Foods for Human Nutrition 66:224-230.

Mazzeo T, Cauzzi S, Brighenti F, and Pellegrini N. 2015. The development of a composition database of gluten-free products. Public Health Nutr 18:1353-1357.

Mezaize S, Chevallier S, Le Bail A, and De Lamballerie M. 2009. Optimization of gluten-free formulations for French-style breads. Journal of Food Science 74:E140-E146.

Miranda J, Lasa A, Bustamante MA, Churruca I, and Simon E. 2014. Nutritional Differences Between a Gluten-free Diet and a Diet Containing Equivalent Products with Gluten. Plant Foods for Human Nutrition 69:182-187.

Molina-Infante J, Santolaria S, Sanders D, and Fernández-Bañares F. 2015. Systematic review: noncoeliac gluten sensitivity. Alimentary pharmacology \& therapeutics 41:807-820.

Mulder CJ, Wierdsma NJ, Berkenpas M, Jacobs MAJM, and Bouma G. 2015. Preventing complications in celiac disease: Our experience with managing adult celiac disease. Best Practice \& Research Clinical Gastroenterology 29:459-468.

Nutrition and Health Claim N¹924/2006. 2006. Nutrition Claims and Conditions Applying to them as listed in the Annex of Regulation (EC) N¹924/2006:L404/409-L404/425.

Open Science Framework. https://osf.io/. (accessed 23 September)

Pellegrini N, and Agostoni C. 2015. Nutritional aspects of gluten-free products. Journal of the Science of Food and Agriculture.

Pennington JA. 2008. Applications of food composition data: Data sources and considerations for use. Journal of Food Composition and Analysis 21:S3-S12.

Rubio-Tapia A, Hill ID, Kelly CP, Calderwood AH, and Murray JA. 2013. ACG clinical guidelines: Diagnosis and management of celiac disease. American Journal of Gastroenterology 108:656-676.

Peer] reviewing PDF | (2015:06:5582:1:0:NEW 23 Sep 2015) 
Sapone A, Bai JC, Ciacci C, Dolinsek J, Green PH, Hadjivassiliou M, Kaukinen K, Rostami K, Sanders DS, Schumann M, Ullrich R, Villalta D, Volta U, Catassi C, and Fasano A. 2012. Spectrum of glutenrelated disorders: consensus on new nomenclature and classification. BMC Med 10:13.

Saturni L, Ferretti G, and Bacchetti T. 2010. The gluten-free diet: Safety and nutritional quality. Nutrients 2:16-34.

Silvester J, Weiten D, Graff L, Walker J, and Duerksen D. 2015. Living gluten-free: adherence, knowledge, lifestyle adaptations and feelings towards a gluten-free diet. Journal of Human Nutrition and Dietetics.

Singh J, and Whelan K. 2011. Limited availability and higher cost of gluten-free foods. Journal of Human Nutrition and Dietetics 24:479-486.

Staudacher HM, and Gibson PR. 2015. How healthy is a gluten-free diet? Br J Nutr:1-3.

Stevens L, and Rashid M. 2008. Gluten-free and regular foods: a cost comparison. Canadian Journal of Dietetic Practice and Research 69:147-150.

Strom S. A big bet on gluten-free. New York Times, 17 February. 2014 (accessed, 21. July 2015)

Theethira TG, and Dennis M. 2015. Celiac Disease and the Gluten-Free Diet: Consequences and Recommendations for Improvement. Digestive Diseases 33:175-182.

van Hees NJM, Giltay EJ, Tielemans SMAJ, Geleijnse JM, Puvill T, Janssen N, and Does Wvd. 2015. Essential Amino Acids in the Gluten-Free Diet and Serum in Relation to Depression in Patients with Celiac Disease. PLoS One 10:e0122619.

Wu JH, Neal B, Trevena H, Crino M, Stuart-Smith W, Faulkner-Hogg K, Yu Louie JC, and Dunford E. 2015. Are gluten-free foods healthier than non-gluten-free foods? An evaluation of supermarket products in Australia. British Journal of Nutrition 114: 448-454. 
Figure 1 (on next page)

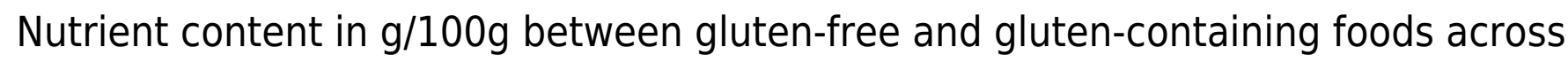
seven different food categories

Notes. Data displayed as mean values. * Significant differences $(p<0.05)$ between gluten-free and gluten containing foods 


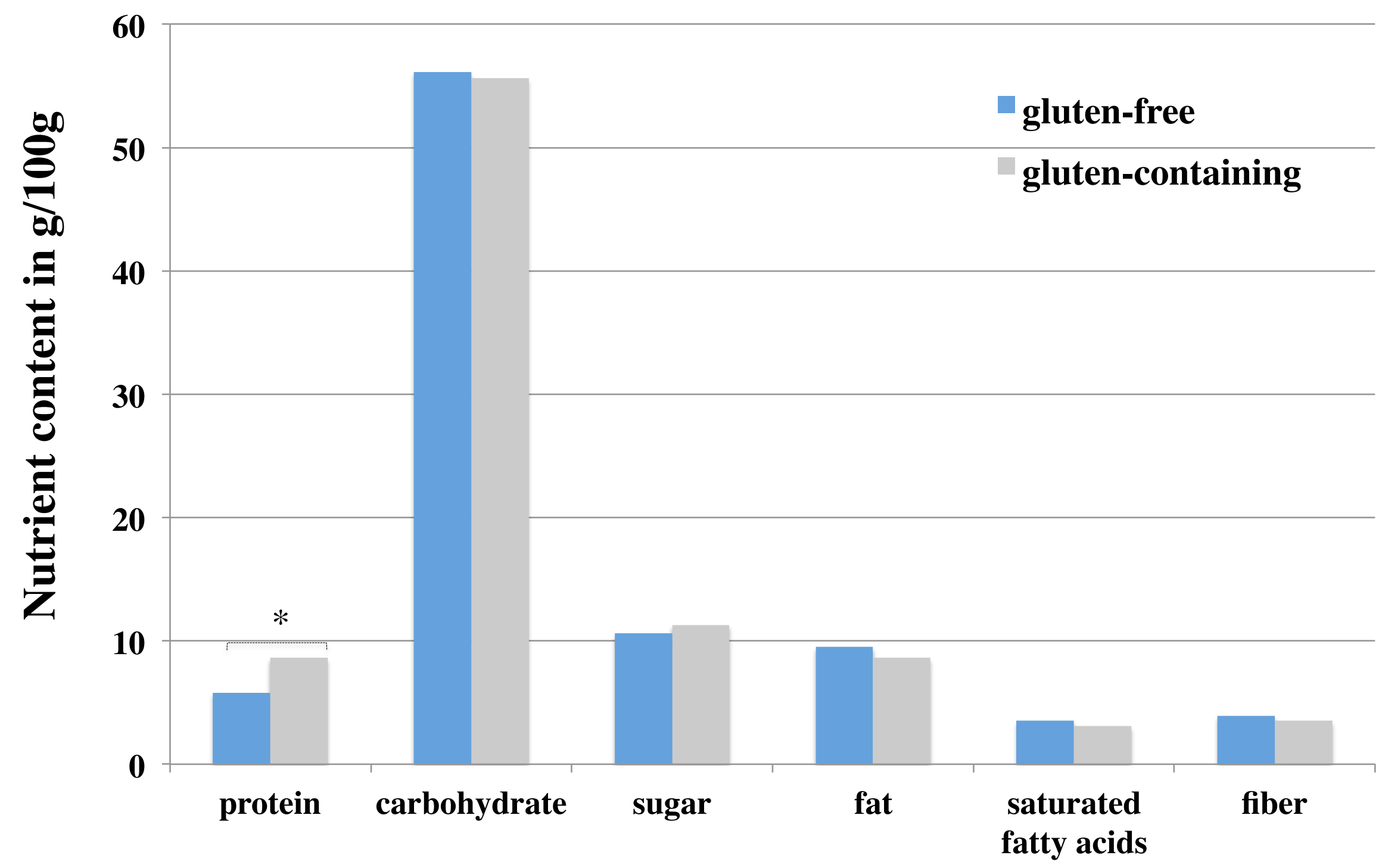


Figure 2 (on next page)

Cost in $€ / \mathrm{kg}$ between gluten-free and gluten-containing foods across seven different food categories

Notes. Data displayed as mean values. Within all food categories differences in mean cost between GF and and gluten-containing foods were significant $(p<0.05)$. 


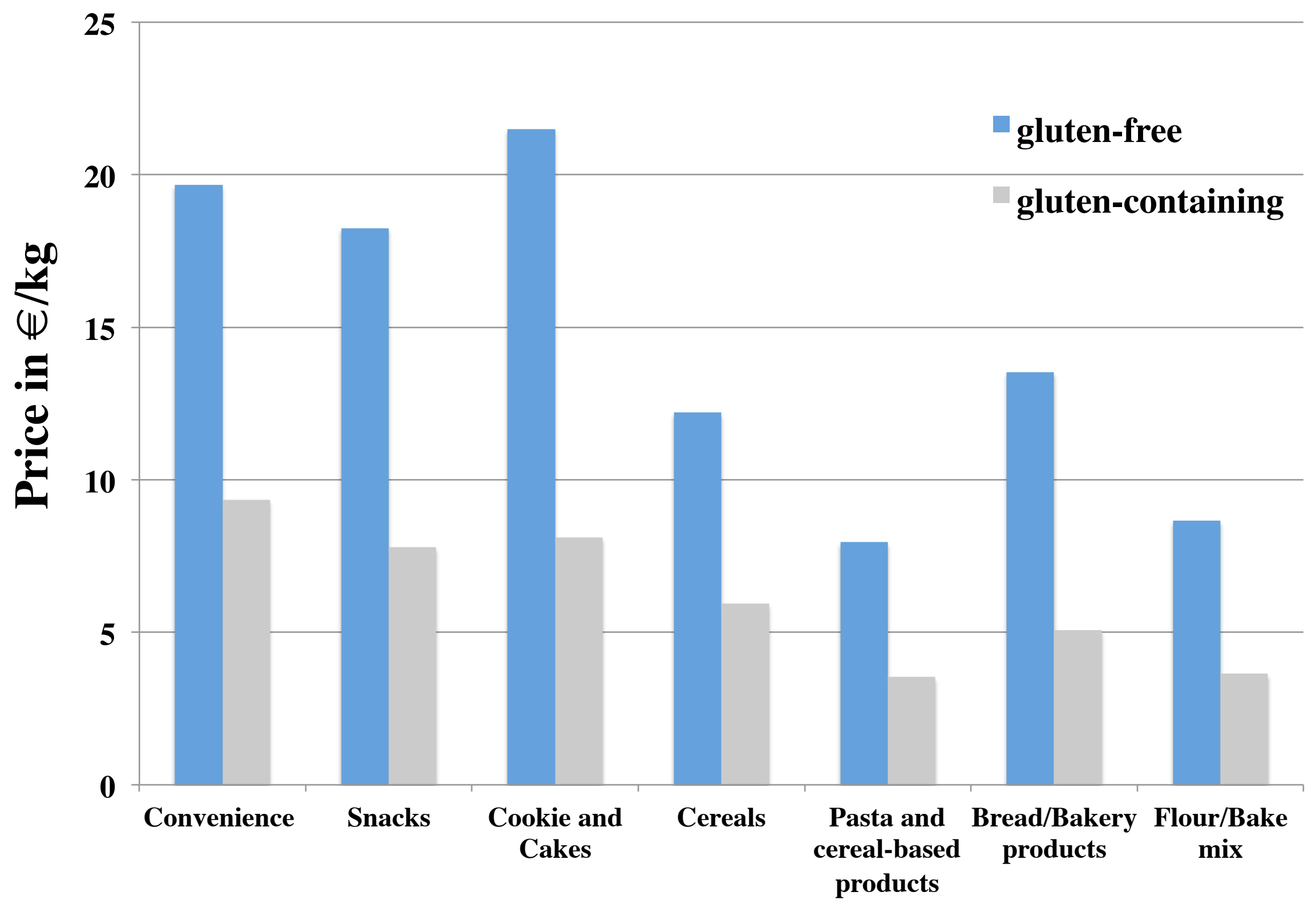


Table $\mathbf{1}$ (on next page)

Macronutrient composition of gluten-free products in Austria.

Notes. Data displayed as mean values. *Mean values of two very similar products were pooled. 
1 Table 1: Macronutrient composition of gluten-free products in Austria. Values expressed as g/100g of the product.

\begin{tabular}{|c|c|c|c|c|c|c|c|c|c|}
\hline & Energy (kcal) & Protein (g) & Carbohydrates (g) & Sugar (g) & Total Fat (g) & $\begin{array}{l}\text { Saturated } \\
\text { fatty acids (g) }\end{array}$ & MUFA (mg) & $\begin{array}{l}\text { PUFA } \\
(\mathrm{mg})\end{array}$ & $\begin{array}{l}\text { Fiber } \\
\text { (g) }\end{array}$ \\
\hline \multicolumn{10}{|l|}{ Flour/Bake mix } \\
\hline Flour * & 345.5 & 3.7 & 77.6 & 1.0 & 1.7 & 0.2 & 0.3 & 1.0 & 3.8 \\
\hline Bake mix white (cake) & 338.4 & 3.2 & 77.5 & 17.8 & 1.2 & 0.3 & 0.5 & 0.5 & 2.3 \\
\hline Bake mix brown (cake) & 394.7 & 2.6 & 82.9 & 52.5 & 5.4 & 3.1 & 1.8 & 0.4 & 2.8 \\
\hline Bake mix (Pizza) $*$ & 322.7 & 5.9 & 70.3 & 1.5 & 1.9 & 0.4 & 0.8 & 0.7 & 3.9 \\
\hline Breadcrumbs * & 350.8 & 5.9 & 70.1 & 0.4 & 4.8 & 1.3 & 1.9 & 1.2 & 6.0 \\
\hline \multicolumn{10}{|l|}{ Bread/Bakery products } \\
\hline Rustic bread & 238.4 & 3.7 & 51.0 & 0.7 & 1.9 & 0.3 & 0.8 & 0.6 & 1.4 \\
\hline Whole-grain bread & 263.6 & 8.5 & 40.8 & 5.1 & 7.2 & 1.0 & 2.2 & 3.9 & 8.4 \\
\hline Toast * & 224.8 & 4.8 & 39.0 & 2.1 & 5.3 & 1.4 & 2.0 & 1.5 & 6.3 \\
\hline Bun & 259.2 & 1.4 & 48.7 & 5.2 & 6.2 & 3.0 & 1.6 & 1.2 & 1.6 \\
\hline Ciabatta & 213.4 & 3.3 & 44.9 & 2.9 & 2.0 & 0.3 & 2.3 & 0.7 & 8.3 \\
\hline Raisin bread & 261.0 & 4.0 & 49.1 & 18.6 & 4.2 & 1.5 & 0.8 & 0.8 & 1.6 \\
\hline Scone & 293.2 & 3.7 & 52.2 & 13.8 & 7.5 & 2.2 & 1.4 & 1.1 & 2.7 \\
\hline Baguette & 270.1 & 4.5 & 56.7 & 6.4 & 2.5 & 0.4 & 1.9 & 3.0 & 5.3 \\
\hline Lye Pretzel & 343.8 & 4.8 & 59.2 & 7.8 & 9.4 & 4.7 & 1.0 & 0.9 & 2.2 \\
\hline Rusk & 343.9 & 0.3 & 82.5 & 0.8 & 0.9 & 0.3 & 3.2 & 0.7 & 0.7 \\
\hline Crispbread & 351.6 & 6.9 & 77.8 & 6.0 & 0.9 & 0.2 & 0.4 & 0.2 & 2.9 \\
\hline Wraps & 228.7 & 3.1 & 38.8 & 0.4 & 7.5 & 2.2 & 0.3 & 0.4 & 2.8 \\
\hline \multicolumn{10}{|c|}{ Pasta and cereal-based products } \\
\hline Fusilli & 335.9 & 8.2 & 69.9 & 1.0 & 2.2 & 0.3 & 0.7 & 1.1 & 7.2 \\
\hline Spaghetti & 329.0 & 8.7 & 66.3 & 1.3 & 2.8 & 0.4 & 0.9 & 1.4 & 9.4 \\
\hline Penne & 338.4 & 6.9 & 72.4 & 4.3 & 1.9 & 0.3 & 0.5 & 0.9 & 4.9 \\
\hline Lasagne sheets & 373.0 & 7.0 & 76.3 & 0.8 & 4.0 & 1.1 & 1.6 & 0.8 & 2.4 \\
\hline Vermicelli & 371.2 & 12.5 & 71.6 & 2.0 & 3.4 & 0.4 & 1.0 & 1.7 & 13.5 \\
\hline Tagliatelli & 370.9 & 12.1 & 72.0 & 1.9 & 3.3 & 0.4 & 1.0 & 1.7 & 13.1 \\
\hline Cous Cous & 345.0 & 8.8 & 73.8 & 1.5 & 1.1 & 0.1 & 0.4 & 0.4 & 5.0 \\
\hline \multicolumn{10}{|l|}{ Cereals } \\
\hline Granola (chocolate) & 392.3 & 5.5 & 72.6 & 34.0 & 8.5 & 4.7 & 3.1 & 0.6 & 4.6 \\
\hline Granola (nuts) & 478.0 & 7.1 & 64.9 & 16.7 & 21.0 & 7.7 & 10.3 & 2.5 & 4.8 \\
\hline Cornflakes & 322.4 & 8.5 & 62.9 & 1.4 & 3.7 & 0.6 & 1.1 & 1.6 & 7.6 \\
\hline \multicolumn{10}{|l|}{ Cookie and Cakes } \\
\hline Shortbread & 385.3 & 3.3 & 73.6 & 13.8 & 8.3 & 2.7 & 3.9 & 1.5 & 1.2 \\
\hline Neapolitan wafers (original) & 236.0 & 2.5 & 22.9 & 18.1 & 15.0 & 8.3 & 5.2 & 1.1 & 3.3 \\
\hline Cookie (chocolate) & 479.2 & 2.0 & 64.3 & 5.7 & 23.8 & 11.9 & 8.5 & 2.5 & 2.3 \\
\hline Mignon wafers (hazelnut) & 507.9 & 5.0 & 54.0 & 41.7 & 30.4 & 13.9 & 11.9 & 3.7 & 5.6 \\
\hline Marble cake & 403.7 & 5.4 & 48.1 & 20.7 & 22.6 & 3.8 & 10.2 & 7.4 & 0.8 \\
\hline Ladyfinger & 356.9 & 5.7 & 74.6 & 33.1 & 3.5 & 1.0 & 1.4 & 0.6 & 2.5 \\
\hline Cookie (whole-grain) & 471.1 & 4.6 & 71.8 & 21.1 & 18.2 & 7.8 & 6.8 & 2.8 & 3.6 \\
\hline Granola bar & 400.8 & 7.2 & 59.2 & 25.0 & 14.8 & 7.0 & 5.3 & 1.7 & 12.9 \\
\hline Cookie (orange)* & 433.0 & 6.2 & 60.2 & 49.7 & 18.3 & 10.5 & 5.5 & 1.4 & 2.6 \\
\hline Apple strudel & 270.9 & 4.2 & 43.2 & 18.1 & 8.7 & 3.4 & 2.9 & 2.2 & 1.6 \\
\hline Muffin & 371.6 & 5.2 & 55.8 & 30.0 & 14.6 & 4.1 & 3.4 & 2.2 & 3.5 \\
\hline
\end{tabular}




\begin{tabular}{|c|c|c|c|c|c|c|c|c|c|}
\hline Snacks & & & & & & & & & \\
\hline Cracker & 340.8 & 10.1 & 43.5 & 0.0 & 13.8 & 9.3 & 3.3 & 0.4 & 0.3 \\
\hline Brezels & 449.7 & 0.5 & 65.5 & 0.8 & 20.6 & 9.8 & 7.5 & 2.4 & 0.8 \\
\hline Grissini & 392.5 & 2.0 & 67.4 & 2.6 & 12.6 & 3.9 & 6.1 & 2.4 & 0.7 \\
\hline Saltsticks & 480.9 & 0.6 & 72.0 & 1.5 & 21.1 & 10.3 & 7.8 & 2.2 & 0.8 \\
\hline Wafers (plain) & 329.7 & 8.6 & 63.8 & 1.4 & 4.1 & 0.6 & 1.2 & 1.8 & 7.7 \\
\hline \multicolumn{10}{|l|}{ Convenience foods } \\
\hline Pizza (salami) & 235.1 & 8.0 & 24.8 & 2.8 & 11.5 & 4.8 & 4.1 & 1.9 & 1.5 \\
\hline Pizza (margherita) & 209.1 & 6.3 & 27.6 & 3.5 & 8.0 & 3.8 & 2.5 & 1.3 & 2.0 \\
\hline Lasagne & 170.4 & 7.4 & 16.4 & 2.2 & 8.3 & 3.8 & 3.2 & 0.8 & 1.1 \\
\hline Chicken Nuggets & 251.2 & 15.3 & 22.5 & 0.5 & 11.0 & 1.5 & 4.2 & 4.8 & 3.0 \\
\hline Fish sticks & 216.0 & 9.2 & 28.1 & 4.0 & 7.3 & 0.8 & 1.8 & 3.8 & 1.9 \\
\hline Tortellini (pork) & 285.3 & 7.7 & 48.1 & 1.3 & 6.6 & 2.5 & 2.5 & 1.0 & 1.7 \\
\hline Soup (potato and leek) & 355.9 & 16.2 & 47.7 & 7.9 & 10.4 & 2.2 & 4.3 & 2.6 & 8.3 \\
\hline Soup (mushrooms) & 431.4 & 15.5 & 43.4 & 13.7 & 21.7 & 2.1 & 10.2 & 5.7 & 1.6 \\
\hline Wafer-cone (icecream filling) & 278.0 & 5.2 & 27.8 & 24.2 & 16.2 & 5.9 & 7.0 & 2.9 & 3.5 \\
\hline Pudding (semolina) & 362.5 & 6.2 & 82.0 & 14.8 & 0.6 & 0.1 & 0.2 & 0.2 & 1.8 \\
\hline Baked pastry case & 483.9 & 4.3 & 43.3 & 21.6 & 32.9 & 15.7 & 12.0 & 3.6 & 4.4 \\
\hline Wafer (Oblate) & 329.2 & 1.1 & 79.1 & 0.2 & 0.4 & 0.1 & 0.1 & 0.2 & 1.2 \\
\hline Rice Drink (natural) & 56.9 & 1.1 & 11.0 & 0.2 & 0.9 & 0.1 & 0.4 & 0.3 & 0.4 \\
\hline Flaky pastry & 389.5 & 1.4 & 31.6 & 2.05 & 29.0 & 8.1 & 7.3 & 12.3 & 5.3 \\
\hline Frozen Cake (almond, chocolate) & 405.2 & 7.0 & 25.1 & 24.4 & 31.1 & 10.9 & 13.1 & 4.3 & 2.0 \\
\hline
\end{tabular}

3

4 Notes. *mean values of two very similar products were pooled. 
Table 2 (on next page)

Micronutrient composition of gluten-free products in Austria.

Notes. Data displayed as mean values. *Mean values of two very similar products were pooled. 
1 Table 2: Micronutrient composition of gluten-free products in Austria. Values expressed as g/100g of the product.

\begin{tabular}{|c|c|c|c|c|c|c|c|c|c|c|c|c|c|c|c|}
\hline & $\begin{array}{r}\text { Sodiu } \\
\mathbf{m} \\
(\mathbf{m g})\end{array}$ & $\begin{array}{l}\text { Cholesto } \\
\text { rol (mg) }\end{array}$ & $\begin{array}{l}\text { Iron } \\
\text { (mg) }\end{array}$ & $\begin{array}{l}\text { Calciu } \\
\mathrm{m}(\mathrm{mg})\end{array}$ & $\begin{array}{r}\text { Potassiu } \\
\mathrm{m}(\mathrm{mg})\end{array}$ & $\begin{array}{l}\text { Zinc } \\
\text { (mg) }\end{array}$ & $\begin{array}{r}\text { Phospho } \\
\text { r (mg) }\end{array}$ & $\begin{array}{r}\text { Vitamin } \\
\text { C (mg) }\end{array}$ & $\begin{array}{r}\text { Vitamin } \\
D(\mu g)\end{array}$ & $\begin{array}{r}\text { Vitamin } \\
\text { E (mg) }\end{array}$ & $\begin{array}{r}\text { Retinol } \\
(\mu \mathrm{g})\end{array}$ & $\begin{array}{r}\beta- \\
\text { Carotin } \\
(\mu \mathrm{g})\end{array}$ & $\begin{array}{r}\text { Thiamin } \\
\text { (mg) }\end{array}$ & $\begin{array}{r}\text { Riboflavi } \\
\text { n (mg) }\end{array}$ & $\begin{array}{r}\text { Niacin } \\
(\mathrm{mg})\end{array}$ \\
\hline \multicolumn{16}{|l|}{ Flour/Bake mix } \\
\hline Flour * & 3.02 & 0.00 & 1.42 & 32.16 & 147.84 & 0.99 & 78.76 & 0.00 & 0.00 & 0.11 & 0.00 & 0.02 & 0.08 & 0.03 & 0.29 \\
\hline Bake mix white (cake) & 39.67 & 0.00 & 1.17 & 54.73 & 240.21 & 1.08 & 204.11 & 0.12 & 0.00 & 0.04 & 0.00 & 0.00 & 0.03 & 0.02 & 0.29 \\
\hline Bake mix brown (cake) & 41.71 & 9.47 & 1.23 & 17.52 & 252.71 & 0.79 & 118.76 & 0.32 & 0.00 & 0.06 & 0.00 & 0.00 & 0.02 & 0.02 & 0.29 \\
\hline Bake mix (Pizza) * & 783.75 & 0.00 & 1.49 & 89.31 & 347.84 & 1.64 & 720.85 & 0.39 & 0.00 & 0.08 & 0.00 & 0.00 & 0.06 & 0.05 & 1.14 \\
\hline Breadcrumbs * & 196.33 & 0.04 & 2.25 & 31.67 & 182.99 & 1.88 & 183.23 & 0.00 & 0.00 & 1.02 & 0.00 & 4.51 & 0.25 & 0.04 & 0.31 \\
\hline \multicolumn{16}{|l|}{ Bread/Bakery products } \\
\hline Rustic bread & 120.53 & 0.00 & 0.38 & 10.58 & 75.45 & 0.48 & 35.90 & 0.00 & 0.00 & 1.01 & 0.00 & 0.00 & 0.06 & 0.02 & 0.48 \\
\hline Whole-grain bread & 685.79 & 0.00 & 2.41 & 96.43 & 304.10 & 1.70 & 208.75 & 0.01 & 0.00 & 0.23 & 0.00 & 0.01 & 0.21 & 0.10 & 1.33 \\
\hline Toast * & 394.29 & 0.02 & 1.58 & 34.01 & 273.02 & 1.24 & 135.35 & 0.03 & 0.00 & 2.05 & 0.00 & 0.37 & 0.17 & 0.11 & 1.92 \\
\hline Bun & 402.11 & 4.02 & 0.60 & 17.67 & 52.68 & 0.39 & 36.52 & 0.00 & 0.00 & 0.48 & 0.00 & 1.28 & 0.03 & 0.06 & 0.48 \\
\hline Ciabatta & 355.74 & 0.00 & 1.03 & 17.15 & 117.38 & 0.86 & 91.38 & 1.20 & 0.00 & 1.05 & 0.00 & 0.08 & 0.14 & 0.09 & 0.97 \\
\hline Raisin bread & 299.48 & 0.37 & 1.01 & 59.31 & 157.72 & 0.73 & 80.86 & 0.43 & 0.00 & 0.08 & 0.02 & 0.04 & 0.07 & 0.09 & 0.51 \\
\hline Scone & 314.90 & 32.64 & 0.82 & 30.76 & 91.38 & 0.50 & 73.71 & 0.01 & 0.00 & 0.19 & 0.06 & 0.05 & 0.07 & 0.14 & 1.09 \\
\hline Baguette & 336.38 & 0.00 & 0.66 & 13.96 & 120.93 & 0.41 & 48.25 & 0.84 & 0.00 & 1.41 & 0.00 & 0.01 & 0.07 & 0.06 & 0.62 \\
\hline Lye Pretzel & 790.76 & 7.06 & 0.40 & 124.30 & 137.68 & 0.57 & 78.43 & 13.10 & 0.00 & 0.49 & 0.02 & 1.29 & 0.04 & 0.15 & 0.15 \\
\hline Rusk & 5.52 & 0.01 & 1.06 & 21.34 & 11.95 & 0.40 & 20.24 & 0.00 & 0.00 & 0.08 & 0.00 & 1.00 & 0.00 & 0.01 & 0.09 \\
\hline Crispbread & 547.20 & 0.00 & 0.67 & 11.61 & 99.13 & 0.67 & 109.04 & 0.00 & 0.00 & 0.24 & 0.00 & 0.04 & 0.11 & 0.04 & 1.38 \\
\hline Wraps & 402.35 & 0.63 & 0.21 & 18.09 & 83.57 & 0.19 & 39.96 & 0.25 & 0.23 & 0.07 & 0.05 & 0.06 & 0.03 & 0.01 & 0.58 \\
\hline \multicolumn{16}{|l|}{$\begin{array}{r}\text { Pasta and cereal-based } \\
\text { products }\end{array}$} \\
\hline Fusilli & 1.88 & 0.00 & 1.80 & 14.67 & 114.68 & 1.87 & 205.75 & 0.00 & 0.00 & 0.81 & 0.00 & 0.21 & 0.33 & 0.10 & 1.76 \\
\hline Spaghetti & 1.00 & 0.00 & 2.40 & 18.00 & 120.00 & 2.50 & 256.00 & 0.00 & 0.00 & 1.11 & 0.00 & 0.30 & 0.44 & 0.13 & 1.93 \\
\hline Penne & 1.90 & 0.00 & 3.15 & 22.73 & 198.37 & 1.43 & 211.40 & 0.00 & 0.00 & 0.48 & 0.00 & 0.12 & 0.28 & 0.12 & 1.61 \\
\hline Lasagne sheets & 55.98 & 146.52 & 1.37 & 30.53 & 91.97 & 1.32 & 144.47 & 0.00 & 0.00 & 0.89 & 0.10 & 0.04 & 0.10 & 0.18 & 0.52 \\
\hline Vermicelli & 6.71 & 0.00 & 3.81 & 45.15 & 297.12 & 3.05 & 327.38 & 0.93 & 0.00 & 1.68 & 0.00 & 0.31 & 0.51 & 0.16 & 2.14 \\
\hline Tagliatelli & 5.94 & 0.00 & 3.65 & 41.70 & 274.68 & 3.02 & 321.78 & 0.80 & 0.00 & 1.62 & 0.00 & 0.32 & 0.51 & 0.16 & 2.14 \\
\hline Cous Cous & 1.00 & 0.00 & 1.00 & 4.00 & 80.00 & 0.41 & 73.00 & 0.00 & 0.00 & 0.52 & 0.00 & 0.26 & 0.13 & 0.04 & 1.20 \\
\hline \multicolumn{16}{|l|}{ Cereals } \\
\hline Granola (chocolate) & 504.01 & 15.77 & 1.51 & 17.98 & 265.98 & 0.52 & 73.86 & 0.13 & 0.00 & 0.25 & 0.00 & 0.51 & 0.05 & 0.06 & 0.96 \\
\hline Granola (nuts) & 393.96 & 0.16 & 1.72 & 44.88 & 314.76 & 1.60 & 174.62 & 0.11 & 0.00 & 3.54 & 0.00 & 1.78 & 0.20 & 0.09 & 1.40 \\
\hline Cornflakes & 575.88 & 0.00 & 1.52 & 8.61 & 265.44 & 1.45 & 208.76 & 0.00 & 0.00 & 1.47 & 0.00 & 0.90 & 0.35 & 0.20 & 1.47 \\
\hline \multicolumn{16}{|l|}{ Cookie and Cakes } \\
\hline Shortbread & 408.14 & 17.31 & 0.66 & 33.19 & 79.97 & 0.59 & 72.93 & 0.22 & 0.00 & 0.84 & 0.02 & 9.02 & 0.05 & 0.10 & 0.73 \\
\hline $\begin{array}{r}\text { Neapolitan wafers } \\
\text { (original) }\end{array}$ & 16.20 & 21.70 & 0.71 & 8.86 & 259.18 & 0.59 & 61.06 & 0.01 & 0.00 & 0.12 & 0.00 & 0.01 & 0.03 & 0.03 & 0.37 \\
\hline Cookie (chocolate) & 199.30 & 3.37 & 0.82 & 13.20 & 91.10 & 0.73 & 57.96 & 0.00 & 0.00 & 1.66 & 0.00 & 4.50 & 0.05 & 0.02 & 0.26 \\
\hline Mignon wafers (hazelnut) & 417.91 & 28.84 & 2.70 & 28.12 & 476.92 & 1.16 & 124.82 & 0.02 & 0.00 & 1.31 & 0.00 & 0.03 & 0.09 & 0.06 & 0.68 \\
\hline Marble cake & 54.88 & 138.60 & 1.32 & 22.11 & 103.26 & 0.76 & 98.91 & 0.00 & 0.00 & 12.54 & 0.10 & 0.02 & 0.05 & 0.15 & 0.24 \\
\hline Ladyfinger & 98.46 & 141.37 & 1.00 & 37.26 & 79.88 & 0.80 & 100.96 & 0.00 & 0.00 & 0.72 & 0.10 & 0.00 & 0.05 & 0.15 & 0.28 \\
\hline Cookie (whole-grain) & 295.19 & 5.16 & 1.17 & 15.24 & 68.83 & 0.78 & 89.30 & 0.13 & 0.00 & 0.37 & 0.00 & 0.12 & 0.14 & 0.05 & 0.87 \\
\hline Granola bar & 237.91 & 4.24 & 2.14 & 96.16 & 292.51 & 1.37 & 170.55 & 0.45 & 0.00 & 1.00 & 0.01 & 0.16 & 0.19 & 0.19 & 1.23 \\
\hline Cookie (orange)* & 190.66 & 23.28 & 1.74 & 103.46 & 389.10 & 0.83 & 120.50 & 4.78 & 0.00 & 0.39 & 0.06 & 0.27 & 0.08 & 0.13 & 0.45 \\
\hline Apple strudel & 102.98 & 1.83 & 1.13 & 177.03 & 240.82 & 0.68 & 128.36 & 4.75 & 0.00 & 0.16 & 0.05 & 0.08 & 0.07 & 0.27 & 0.25 \\
\hline Muffin & 247.84 & 79.20 & 2.66 & 29.50 & 219.98 & 0.74 & 102.31 & 0.00 & 0.00 & 3.54 & 0.06 & 0.01 & 0.06 & 0.11 & 0.30 \\
\hline \multicolumn{16}{|l|}{ Snacks } \\
\hline Cracker & $\begin{array}{r}2416.3 \\
6\end{array}$ & 47.71 & 1.40 & 434.99 & 83.08 & 2.05 & 305.78 & 0.43 & 0.00 & 0.41 & 0.13 & 0.06 & 0.03 & 0.12 & 0.48 \\
\hline
\end{tabular}




\begin{tabular}{|c|c|c|c|c|c|c|c|c|c|c|c|c|c|c|c|}
\hline Brezels & 554.28 & 0.20 & 0.67 & 11.72 & 17.23 & 0.45 & 26.93 & 0.00 & 0.00 & 1.48 & 0.00 & 4.26 & 0.01 & 0.03 & 0.21 \\
\hline Grissini & 226.87 & 20.01 & 0.63 & 52.59 & 64.73 & 0.62 & 62.82 & 0.06 & 0.00 & 1.31 & 0.03 & 15.02 & 0.02 & 0.09 & 0.07 \\
\hline Saltsticks & $\begin{array}{r}1007.3 \\
6\end{array}$ & 0.21 & 0.93 & 15.82 & 25.22 & 0.47 & 30.69 & 0.00 & 0.00 & 1.56 & 0.00 & 4.47 & 0.02 & 0.04 & 0.34 \\
\hline Wafers (plain) & 119.98 & 0.01 & 1.50 & 8.15 & 268.55 & 1.47 & 211.73 & 0.02 & 0.00 & 1.61 & 0.00 & 0.92 & 0.36 & 0.20 & 1.49 \\
\hline \multicolumn{16}{|l|}{ Convenience foods } \\
\hline Pizza (salami) & 614.15 & 22.66 & 0.97 & 103.75 & 275.57 & 1.13 & 115.28 & 7.43 & 0.00 & 3.23 & 0.04 & 0.24 & 0.11 & 0.11 & 1.68 \\
\hline Pizza (margherita) & 437.51 & 14.95 & 0.68 & 110.73 & 266.87 & 0.85 & 106.10 & 6.97 & 0.00 & 2.97 & 0.05 & 0.26 & 0.05 & 0.10 & 1.02 \\
\hline $\begin{array}{l}\text { Lasagne } \\
\end{array}$ & 450.21 & 38.88 & 0.79 & 56.08 & 211.47 & 1.38 & 99.60 & 5.51 & 0.02 & 1.14 & 0.04 & 0.24 & 0.11 & 0.13 & 1.51 \\
\hline Nuggets & 396.19 & 35.00 & 1.34 & 16.80 & 158.47 & 1.37 & 179.53 & 0.05 & 0.00 & 5.46 & 0.00 & 0.16 & 0.14 & 0.09 & 4.71 \\
\hline $\begin{array}{l}\text { Fish sticks } \\
\end{array}$ & 378.34 & 23.54 & 1.19 & 24.87 & 128.33 & 0.49 & 142.50 & 0.24 & 0.00 & 4.04 & 0.00 & 0.11 & 0.12 & 0.22 & 1.62 \\
\hline Tortellini (pork) & 628.05 & 72.33 & 1.49 & 51.06 & 118.68 & 1.64 & 122.19 & 1.06 & 0.01 & 0.75 & 0.04 & 0.04 & 0.24 & 0.12 & 1.38 \\
\hline Soup (potato and leek) & $\begin{array}{r}3801.7 \\
6 \\
\end{array}$ & 1.03 & 2.53 & 80.57 & 1014.25 & 0.88 & 260.47 & 11.70 & 0.00 & 1.61 & 0.00 & 0.42 & 0.17 & 0.28 & 4.63 \\
\hline Soup (mushrooms) & 472.57 & 0.43 & 0.89 & 17.52 & 104.01 & 0.22 & 34.90 & 0.95 & 0.00 & 3.82 & 0.00 & 0.68 & 0.04 & 0.07 & 0.91 \\
\hline $\begin{array}{r}\begin{array}{r}\text { Wafer-cone (icecream } \\
\text { filling) }\end{array} \\
\end{array}$ & 101.42 & 22.61 & 1.39 & 97.43 & 358.09 & 0.78 & 127.37 & 0.81 & 0.12 & 3.66 & 0.02 & 0.04 & 0.04 & 0.16 & 0.37 \\
\hline Pudding (semolina) & 117.48 & 0.00 & 0.54 & 9.64 & 91.27 & 0.50 & 79.69 & 0.10 & 0.00 & 0.09 & 0.00 & 0.00 & 0.06 & 0.02 & 1.18 \\
\hline Baked pastry case & 108.30 & 0.32 & 1.61 & 30.08 & 138.24 & 1.30 & 202.23 & 0.70 & 0.00 & 2.87 & 0.00 & 6.82 & 0.18 & 0.09 & 1.91 \\
\hline Wafer (Oblate) & 6.98 & 0.00 & 1.80 & 31.88 & 26.15 & 0.43 & 35.54 & 0.00 & 0.00 & 0.12 & 0.00 & 0.03 & 0.05 & 0.02 & 0.33 \\
\hline Rice Drink (natural) & 52.58 & 0.00 & 0.23 & 12.47 & 17.01 & 0.20 & 15.55 & 0.00 & 0.00 & 0.51 & 0.00 & 0.00 & 0.01 & 0.00 & 0.19 \\
\hline Flaky pastry & 412.00 & 2.35 & 0.22 & 49.65 & 47.07 & 0.20 & 24.56 & 0.13 & 0.03 & 2.10 & 0.00 & 0.17 & 0.24 & 0.01 & 0.22 \\
\hline $\begin{array}{r}\text { Frozen Cake (almond, } \\
\text { chocolate) }\end{array}$ & 120.14 & 170.20 & 1.69 & 39.44 & 219.39 & 0.90 & 126.96 & 0.21 & 0.13 & 4.26 & 0.15 & 2.19 & 0.06 & 0.16 & 0.38 \\
\hline
\end{tabular}

4 Notes. *mean values of two very similar products were pooled. 
Table 3 (on next page)

Comparison between micro-and macronutrient composition of gluten-free and matched gluten-containing foods among categories.

Notes. Data displayed as mean values per unit/100g \pm standard deviation.P† Differences in mean nutrient content between GF and non-GF products were assessed by unpaired t-test. 
1 Table 3: Comparison between micro-and macronutrient composition of gluten-free and matched gluten-containing foods among

2 categories.

\begin{tabular}{|c|c|c|c|c|c|c|c|c|}
\hline & & Flour/Bake mix & $\begin{array}{l}\text { Bread/Bakery } \\
\text { products }\end{array}$ & $\begin{array}{l}\text { Pasta and cereal- } \\
\text { based products }\end{array}$ & Cereals & $\begin{array}{l}\text { Cookie and } \\
\text { Cakes }\end{array}$ & Snacks & $\begin{array}{l}\text { Convenience } \\
\text { foods }\end{array}$ \\
\hline \multirow{3}{*}{ Energy (kcal) } & Gluten Free & $346.4 \pm 35.5$ & $270.5 \pm 46.7$ & $351.9 \pm 17.7$ & $397.5 \pm 63.6$ & $395.8 \pm 84.4$ & $398.7 \pm 59.2$ & $297.3 \pm 108.5$ \\
\hline & Gluten-containing & $335.0 \pm 23.0$ & $280.9 \pm 49.8$ & $346.5 \pm 10.9$ & $397.4 \pm 56.3$ & $416.3 \pm 78.1$ & $371.6 \pm 45.3$ & $298.2 \pm 102.0$ \\
\hline & $\mathbf{P} \dot{\dagger}$ & 0.373 & 0.543 & 0.426 & 0.997 & 0.488 & 0.376 & 0.978 \\
\hline \multirow[t]{3}{*}{ Protein (g) } & Gluten Free & $4.6 \pm 3.2$ & $4.1 \pm 2.2$ & $9.2 \pm 2.1$ & $7.0 \pm 1.2$ & $4.8 \pm 1.6$ & $4.3 \pm 4.1$ & $7.4 \pm 4.8$ \\
\hline & Gluten-containing & $10.0 \pm 2.0$ & $8.3 \pm 1.0$ & $11.9 \pm 0.9$ & $9.2 \pm 2.4$ & $5.8 \pm 1.9$ & $10.5 \pm 1.4$ & $8.2 \pm 3.9$ \\
\hline & $\mathbf{P} \dagger$ & $<0.01$ & $<0.01$ & $<0.05$ & 0.245 & 0.105 & $<0.01$ & 0.605 \\
\hline \multirow[t]{3}{*}{ Carbohydrates (g) } & Gluten Free & 74.4 & 52.3 & 71.7 & 66.7 & 57.3 & 62.4 & 37.2 \\
\hline & Gluten-containing & 67.8 & 52.7 & 69.4 & 57.6 & 59.9 & 61.4 & 39.5 \\
\hline & $\mathrm{P}_{\dagger}$ & $<0.05$ & 0.912 & $<0.05$ & 0.101 & 0.561 & 0.860 & 0.733 \\
\hline \multirow[t]{3}{*}{ Sugar (g) } & Gluten Free & $9.5 \pm 17.2$ & $5.5 \pm 5.2$ & $1.8 \pm 1.1$ & $17.4 \pm 13.3$ & $27.2 \pm 14.6$ & $1.3 \pm 0.8$ & $8.2 \pm 8.8$ \\
\hline & Gluten-containing & $6.0 \pm 9.1$ & $4.4 \pm 5.4$ & $0.8 \pm 0.2$ & $14.5 \pm 6.4$ & $33.7 \pm 12.6$ & $1.0 \pm 0.2$ & $9.8 \pm 12.2$ \\
\hline & $\mathrm{P} \dagger$ & 0.543 & 0.912 & $<0.05$ & 0.714 & 0.188 & $<0.860$ & 0.655 \\
\hline \multirow[t]{3}{*}{ Total Fat (g) } & Gluten Free & $2.9 \pm 2.2$ & $4.7 \pm 2.7$ & $2.7 \pm 0.9$ & $11.1 \pm 7.3$ & $16.4 \pm 8.4$ & $14.4 \pm 6.2$ & $13.1 \pm 10.5$ \\
\hline & Gluten-containing & $2.2 \pm 2.3$ & $3.8 \pm 2.8$ & $1.9 \pm 1.0$ & $14.3 \pm 8.0$ & $17.0 \pm 8.4$ & $9.0 \pm 8.0$ & $11.6 \pm 9.0$ \\
\hline & $\mathbf{P} \dagger$ & 0.481 & 0.349 & 0.133 & 0.621 & 0.852 & 0.238 & 0.630 \\
\hline \multirow{3}{*}{$\begin{array}{l}\text { Saturated fatty } \\
\text { acids (g) }\end{array}$} & Gluten Free & $0.9 \pm 1.1$ & $1.4 \pm 1.3$ & $0.4 \pm 0.3$ & $4.3 \pm 2.9$ & $7.1 \pm 5.1$ & $6.8 \pm 3.8$ & $4.1 \pm 4.3$ \\
\hline & Gluten-containing & $0.7 \pm 1.2$ & $0.9 \pm 1.0$ & $0.4 \pm 0.3$ & $4.4 \pm 3.4$ & $6.8 \pm 4.5$ & $4.2 \pm 5.3$ & $4.0 \pm 4.1$ \\
\hline & $\mathrm{P}_{\dagger}^{\dagger}$ & 0.716 & 0.183 & 0.818 & 0.986 & 0.868 & 0.384 & 0.917 \\
\hline \multirow[t]{3}{*}{ MUFA (mg) } & Gluten Free & $1.0 \pm 1.1$ & $1.5 \pm 0.8$ & $0.9 \pm 0.4$ & $4.8 \pm 4.0$ & $5.9 \pm 3.2$ & $5.2 \pm 2.6$ & $4.8 \pm 4.1$ \\
\hline & Gluten-containing & $0.5 \pm 0.9$ & $1.3 \pm 1.2$ & $0.4 \pm 0.4$ & $6.4 \pm 4.1$ & $6.7 \pm 3.6$ & $2.7 \pm 2.4$ & $4.5 \pm 3.7$ \\
\hline & $\mathrm{P}_{\dagger}$ & 0.236 & 0.614 & $<0.05$ & 0.627 & 0.509 & 0.117 & 0.783 \\
\hline \multirow[t]{3}{*}{ PUFA (mg) } & Gluten Free & $0.8 \pm 0.6$ & $1.4 \pm 1.1$ & $1.1 \pm 0.4$ & $1.5 \pm 0.8$ & $2.4 \pm 1.7$ & $1.8 \pm 0.7$ & $3.0 \pm 3.0$ \\
\hline & Gluten-containing & $0.6 \pm 0.4$ & $1.0 \pm 0.8$ & $0.8 \pm 0.3$ & $3.2 \pm 0.9$ & $2.6 \pm 1.8$ & $1.4 \pm 1.0$ & $1.9 \pm 1.4$ \\
\hline & $\mathbf{P}_{\dagger}$ & 0.220 & 0.195 & 0.100 & 0.055 & 0.723 & 0.412 & 0.101 \\
\hline \multirow{3}{*}{ Fiber (g) } & Gluten Free & $4.1 \pm 2.9$ & $3.9 \pm 2.7$ & $7.9 \pm 4.0$ & $5.6 \pm 1.4$ & $3.5 \pm 3.1$ & $2.0 \pm 2.8$ & $2.6 \pm 2.0$ \\
\hline & Gluten-containing & $4.0 \pm 2.3$ & $3.3 \pm 1.7$ & $3.7 \pm 0.7$ & $7.4 \pm 1.9$ & $3.5 \pm 3.8$ & $4.6 \pm 3.2$ & $2.4 \pm 2.0$ \\
\hline & $\mathbf{P}_{\dagger}$ & 0.944 & 0.429 & $<0.05$ & 0.247 & 0.979 & 0.188 & 0.669 \\
\hline \multirow[t]{3}{*}{ Sodium (mg) } & Gluten Free & $255.9 \pm 326.9$ & $388.4 \pm 198.3$ & $10.6 \pm 18.6$ & $491.3 \pm 74.8$ & $205.0 \pm 122.6$ & $856.0 \pm 835.0$ & $539.8 \pm 894.2$ \\
\hline & Gluten-containing & $281.6 \pm 294.6$ & $581.9 \pm 284.6$ & $15.8 \pm 18.0$ & $160.7 \pm 127.2$ & $247.8 \pm 394.0$ & $832.1 \pm 626.7$ & $715.8 \pm 1186.1$ \\
\hline & $\mathbf{P}_{\dagger}$ & 0.855 & 0.039 & 0.564 & $<0.05$ & 0.724 & 0.938 & 0.623 \\
\hline \multirow[t]{3}{*}{ Cholestorol (mg) } & Gluten Free & $1.2 \pm 3.1$ & $3.4 \pm 8.7$ & $20.9 \pm 51.3$ & $5.3 \pm 7.4$ & $40.7 \pm 49.0$ & $13.6 \pm 18.7$ & $27.0 \pm 43.1$ \\
\hline & Gluten-containing & $2.6 \pm 7.0$ & $5.5 \pm 12.1$ & $21.5 \pm 42.2$ & $1.4 \pm 2.0$ & $32.4 \pm 38.4$ & $1.5 \pm 2.6$ & $28.5 \pm 41.5$ \\
\hline & $\mathbf{P} \dagger$ & 0.617 & 0.602 & 0.980 & 0.318 & 0.595 & 0.083 & 0.908 \\
\hline \multirow[t]{3}{*}{ Iron (mg) } & Gluten Free & $1.6 \pm 0.8$ & $1.0 \pm 0.7$ & $2.5 \pm 1.0$ & $1.6 \pm 0.1$ & $1.5 \pm 0.7$ & $1.0 \pm 0.4$ & $1.2 \pm 0.6$ \\
\hline & Gluten-containing & $1.6 \pm 1.1$ & $1.2 \pm 0.6$ & $2.5 \pm 0.3$ & $6.1 \pm 7.3$ & $1.6 \pm 1.3$ & $2.2 \pm 1.8$ & $1.4 \pm 1.3$ \\
\hline & $\mathbf{P}_{\dagger}$ & 0.964 & 0.216 & 0.944 & 0.375 & 0.840 & 0.188 & 0.496 \\
\hline \multirow[t]{3}{*}{ Calcium (mg) } & Gluten Free & $47.3 \pm 27.2$ & $37.6 \pm 33.9$ & $25.3 \pm 13.7$ & $23.8 \pm 15.4$ & $55.6 \pm 55.0$ & $104.7 \pm 165.9$ & $48.8 \pm 33.1$ \\
\hline & Gluten-containing & $24.3 \pm 19.1$ & $18.9 \pm 10.8$ & $33.6 \pm 7.6$ & $75.4 \pm 117.0$ & $37.2 \pm 27.5$ & $50.3 \pm 45.1$ & $46.4 \pm 40.0$ \\
\hline & $\mathrm{P} \uparrow$ & $<0.05$ & $<0.05$ & 0.105 & 0.524 & 0.202 & 0.384 & 0.842 \\
\hline \multirow[t]{2}{*}{ Potassium (mg) } & Gluten Free & $231.3 \pm 127.5$ & $138.3 \pm 118.9$ & $168.1 \pm 82.5$ & $282.1 \pm 23.1$ & $224.2 \pm 136.7$ & $91.8 \pm 91.7$ & $211.7 \pm 234.1$ \\
\hline & Gluten-containing & $222.3 \pm 86.8$ & $201.3 \pm 61.0$ & $295.4 \pm 121.2$ & $378.3 \pm 152.7$ & $235.1 \pm 124.3$ & $309.7 \pm 179.8$ & $241.8 \pm 145.4$ \\
\hline
\end{tabular}




\begin{tabular}{|c|c|c|c|c|c|c|c|c|}
\hline & $\mathbf{P} \dagger$ & 0.848 & $<0.05$ & $<0.05$ & 0.370 & 0.818 & 0.352 & 0.607 \\
\hline \multirow[t]{3}{*}{ Zinc (mg) } & Gluten Free & $1.4 \pm 0.8$ & $0.7 \pm 0.5$ & $1.9 \pm 0.9$ & $1.2 \pm 0.5$ & $0.8 \pm 0.2$ & $1.0 \pm 0.6$ & $0.8 \pm 0.5$ \\
\hline & Gluten-containing & $1.2 \pm 1.1$ & $0.8 \pm 0.4$ & $4.6 \pm 0.4$ & $2.6 \pm 1.0$ & $0.8 \pm 0.6$ & $1.6 \pm 1.1$ & $1.0 \pm 0.8$ \\
\hline & $\mathrm{P} \dagger$ & 0.734 & 0.766 & $<0.01$ & 0.078 & 0.930 & 0.370 & 0.346 \\
\hline \multirow[t]{3}{*}{ Phosphor (mg) } & Gluten Free & $286.1 \pm 267.0$ & $84.1 \pm 61.3$ & $220.0 \pm 85.2$ & $152.4 \pm 57.3$ & $104.0 \pm 33.5$ & $127.6 \pm 111.8$ & $111.5 \pm 66.4$ \\
\hline & Gluten-containing & $194.7 \pm 177.1$ & $104.9 \pm 49.2$ & $301.3 \pm 178.4$ & $321.0 \pm 222.1$ & $109.2 \pm 73.7$ & $207.2 \pm 152.4$ & $130.7 \pm 84.6$ \\
\hline & $\mathrm{P}_{\dagger}^{\dagger}$ & 0.350 & 0.247 & 0.290 & 0.292 & 0.823 & 0.352 & 0.456 \\
\hline \multirow[t]{3}{*}{ Vitamin C (mg) } & Gluten Free & $0.2 \pm 0.2$ & $1.2 \pm 3.4$ & $0.2 \pm 0.4$ & $0.1 \pm 0.1$ & $1.3 \pm 2.4$ & $0.1 \pm 0.2$ & $2.4 \pm 3.5$ \\
\hline & Gluten-containing & $0.0 \pm 0.0$ & $1.6 \pm 7.6$ & $1.0 \pm 3.5$ & $22.4 \pm 49.9$ & $2.0 \pm 3.4$ & $0.0 \pm 0.1$ & $16.7 \pm 56.1$ \\
\hline & $\mathbf{P} \uparrow$ & $<0.05$ & 0.885 & 0.612 & 0.516 & 0.512 & 0.404 & 0.341 \\
\hline \multirow[t]{3}{*}{ Vitamin E (mg) } & Gluten Free & $0.3 \pm 0.4$ & $0.7 \pm 0.8$ & $1.0 \pm 0.4$ & $1.8 \pm 1.4$ & $1.9 \pm 3.3$ & $1.3 \pm 0.4$ & $2.4 \pm 1.6$ \\
\hline & Gluten-containing & $0.3 \pm 0.4$ & $0.8 \pm 1.0$ & $1.0 \pm 0.2$ & $2.1 \pm 1.2$ & $2.3 \pm 3.2$ & $0.9 \pm 0.5$ & $1.7 \pm 1.1$ \\
\hline & $\mathrm{P}_{\dagger}^{\dagger}$ & 0.952 & 0.841 & 0.972 & 0.728 & 0.724 & 0.178 & 0.065 \\
\hline \multirow[t]{3}{*}{ B-Carotin (mg) } & Gluten Free & $1.1 \pm 3.0$ & $0.4 \pm 0.5$ & $0.2 \pm 0.1$ & $1.1 \pm 0.5$ & $1.2 \pm 2.7$ & $4.9 \pm 5.3$ & $0.8 \pm 1.7$ \\
\hline & Gluten-containing & $0.0 \pm 0.0$ & $0.2 \pm 0.5$ & $0.1 \pm 0.3$ & $1.2 \pm 1.2$ & $1.1 \pm 1.6$ & $0.4 \pm 0.7$ & $0.9 \pm 1.5$ \\
\hline & $\mathrm{P} \dagger$ & 0.160 & 0.347 & 0.320 & 0.838 & 0.887 & $<0.05$ & 0.786 \\
\hline \multirow[t]{3}{*}{ Niacin (mg) } & Gluten Free & $0.6 \pm 0.4$ & $0.9 \pm 0.7$ & $1.6 \pm 0.5$ & $1.3 \pm 0.2$ & $0.5 \pm 0.3$ & $0.5 \pm 0.5$ & $1.5 \pm 1.4$ \\
\hline & Gluten-containing & $1.5 \pm 1.6$ & $1.6 \pm 0.8$ & $3.6 \pm 2.7$ & $11.0 \pm 22.0$ & $0.7 \pm 0.8$ & $3.3 \pm 3.1$ & $1.8 \pm 1.6$ \\
\hline & $\mathbf{P}_{\dagger}^{\dagger}$ & 0.128 & $<0.05$ & 0.077 & 0.523 & 0.552 & 0.084 & 0.488 \\
\hline
\end{tabular}

4

5 